\title{
Article
}

\section{Effects of a prophylactic knee sleeve on anterior cruciate ligament loading during sport specific movements}

Sinclair, Jonathan Kenneth and Taylor, Paul John

Available at http://clok.uclan.ac.uk/18539/

Sinclair, Jonathan Kenneth ORCID: 0000-0002-2231-3732 and Taylor, Paul John ORCID: 0000-0002-9999-8397 (2017) Effects of a prophylactic knee sleeve on anterior cruciate ligament loading during sport specific movements. Journal of Sport Rehabilitation, 28 (1). pp. 1-19. ISSN 1056-6716

It is advisable to refer to the publisher's version if you intend to cite from the work. http://dx.doi.org/10.1123/jsr.2017-0079

For more information about UCLan's research in this area go to http://www.uclan.ac.uk/researchgroups/ and search for <name of research Group>.

For information about Research generally at UCLan please go to http://www.uclan.ac.uk/research/

All outputs in CLoK are protected by Intellectual Property Rights law, including Copyright law. Copyright, IPR and Moral Rights for the works on this site are retained by the individual authors and/or other copyright owners. Terms and conditions for use of this material are defined in the policies page.

\section{CLoK}

Central Lancashire online Knowledge www.clok.uclan.ac.uk

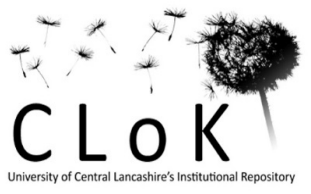


1 Effects of a prophylactic knee sleeve on ACL loading during sport specific movements:

\section{Correspondence Address:}

9 Dr. Jonathan Sinclair

10 Centre for Applied Sport Exercise and Nutritional Sciences

11 School of Sport and Wellbeing

12 Faculty of Health and Wellbeing

13 University of Central Lancashire

14 Preston

15 Lancashire

16 PR1 2HE.

17 e-mail: jksinclair@uclan.ac.uk

\section{Keywords:}

\section{Implications for injury prevention.}

Jonathan Sinclairl \& Paul John Taylor ${ }^{2}$

1. Centre for Applied Sport and Exercise Sciences, School of Sport and Wellbeing, Faculty of Health and Wellbeing, University of Central Lancashire, Lancashire, UK.

2. School of Psychology, Faculty of Science and Technology, University of Central Lancashire, Lancashire, UK. 
22 Abstract

23 The aim of the current investigation was to investigate the effects of a prophylactic knee

24 sleeve on ACL loading parameters linked to the aetiology of injury in recreational athletes.

25 Thirteen male recreational athletes performed run, cut and single leg hop movements under two conditions (prophylactic knee sleeve/ no-sleeve). Biomechanical data was captured using an eight-camera 3D motion capture system and a force platform. ACL loading parameters were examined using 2 (sleeve)*3 (movement) repeated measures ANOVA's. The results showed that both average and instantaneous ACL load rates were significantly reduced when wearing the knee sleeve in the hop $($ sleeve $=612.45 / 1286.39 \mathrm{~N} / \mathrm{kg} / \mathrm{s} \&$ no-sleeve $=743.91 /$ $1471.42 \mathrm{~N} / \mathrm{kg} / \mathrm{s})$ and cut $($ sleeve $=222.55 / 1058.02 \mathrm{~N} / \mathrm{kg} / \mathrm{s} \&$ no-sleeve $=377.38 / 1183.01$ $\mathrm{N} / \mathrm{kg} / \mathrm{s}$ ) movements. Given the biomechanical association between ACL loading and the aetiology of ACL injuries, it is proposed that athletes may be able to attenuate their risk from injury during cut and hop movements through utilization of a prophylactic knee sleeve.

\section{Introduction}

37 Whilst engaging in physical activity and sport is known to mediate a plethora of physiological benefits (Schnohr et al., 2015), participation in sport is also associated with a high risk from injury (Lauersen et al., 2014). Injuries to the anterior cruciate ligament (ACL) are increasing common in those who engage in recreational/ competitive sports activities (Boden et al., 2009). ACL pathologies are extremely serious leading to a long term cessation from training/ competition (Ardern et al., 2011). Furthermore, ACL injury is typically associated with chronic knee discomfort ultimately leads to forced retirement from 
44 competition in many cases (Myklebust \& Bahr, 2004). Importantly Roos et al., (1995) confirmed this assertion in that the findings from their investigation determined that only 30 $\%$ of football players remained active 3 years after suffering an ACL injury. In addition, even following full functional recovery from injury, athletes habitually fail to return to pre-injury levels of performance and it has been demonstrated that statistically significant decrements in performance are evident in relation to non-injured control athletes (Carey et al., 2006).

In addition to the pain/discomfort associated with knee ligament pathologies, more serious long term clinical repercussions are associated with ACL injuries. Athletes who experience ACL injury are up to 10 times more likely to develop early-onset degenerative knee osteoarthritis in comparison to non-injured controls (Øiestad et al., 2009). This ultimately serves to reduce participation in sports activities but also facilitates chronic pain and disability in later life (Ajuied et al., 2014). Clinical studies in the US have shown that over 175,000 ACL reconstruction surgeries are conducted every year, with directly associated direct costs in excess of over $\$ 2$ billion and total allocated costs of $\$ 3.4$ billion (Gottlob et al., 1999).

ACL injuries in athletes are habitually non-contact in nature, in that ligamentous pathology occurs in the absence of any physical interaction between athletes (Boden et al., 2009). Biomechanically, ACL injuries occur when excessive loading is experienced by the ACL itself (Smith et al., 2012). In athletic populations, research has revealed that non-contact ACL injuries predominantly occur in the period immediately preceding foot strike when the knee is in a position close to full extension in sports tasks involving sudden decelerations, landings and pivoting maneuvers (Olsen et al., 2004). It has been demonstrated that most non-contact 
ACL injuries occur in activities that involve single-limb decelerations/ landings (Boden et al., 2009).

Prophylactic knee bracing is extensively utilized in athletic populations in order to reduce the high risk from knee injuries during training/ competition (Sinclair et al., 2017). Prophylactic knee braces are now extremely common and aim to provide protection from injury whilst also being minimally restrictive to the wearer, thus allowing full range of knee motion during their sports specific movements. The majority of research investigating the efficacy of knee bracing in relation to the ACL has examined their effects in those with pre-existing pathologies (either in those with ACL deficiencies or following ACL reconstruction) and there is only limited information concerning their protective effects in healthy athletes. Clinical research into the effects of prophylactic knee bracing on ACL injury rates in athletes has shown in two studies that prophylactic knee bracing did not significantly attenuate the incidence of ACL injuries in athletic populations (Jackson et al., 1991; Sitler et al., 1990). In addition, aetiological investigations have examined the effects of knee bracing on the causative mechanisms of ACL injuries using cadaver based analyses. Erickson et al., (1993) examined the ability of prophylactic knee braces to reduce or limit medial collateral ligament (MCL) and ACL strain under dynamic loading conditions. Their results showed that the braces did not significantly reduce the strain experienced by either the MCL or the ACL. There are currently no biomechanical investigations examining the effects of prophylactic devices on ACL loading magnitudes linked to the aetiology of injury during sport movements using human participants. Furthermore, many prophylactic knee braces that have been examined in previous biomechanical literature concerning the knee ligaments have featured medial and lateral vertical hinges, thus questionable as to whether they are truly nonrestrictive during non-linear sports movements (Raja \& Dewan, 2011). 
94 Therefore the aim of the current investigation was to investigate the effects of a minimally

95 restrictive prophylactic knee sleeve on ACL loading parameters linked to the aetiology of 96 injury in recreational athletes. Research of this nature may provide important clinical

97 information regarding the potential role of prophylactic knee sleeves for the prevention of 98 ACL injuries in recreational athletes.

\section{Methods}

\section{Participants}

Thirteen male recreational athletes $($ age $=23.55 \pm 1.77$ years, height $=1.79 \pm 0.06 \mathrm{~m}$, mass $=$ $71.48 \pm 7.56 \mathrm{~kg}$ ) were recruited to for this study. All participants were free from lower extremity pathology at the time of data collection and had not suffered from a knee injury in the last five years. Written informed consent was provided in accordance with the declaration of Helsinki. The procedure was approved by a university ethics committee (REF 291).

\section{Procedure}

Participants were required to complete five repetitions of three sports specific movements'; jog, cut and single leg hop, with and without presence of a prophylactic knee sleeve (Trizone, DJO USA). To prevent any order effects in the experimental data the manner that participants performed in each movement/ sleeve condition was counterbalanced. Kinematics and ground reaction forces data were synchronously collected using an analogue to digital interface 
115 (Qualisys Medical AB, Goteburg, Sweden), and ground reaction forces via an embedded 116 piezoelectric force platform (Kistler, Kistler Instruments Ltd., Alton, Hampshire) which sampled at $1000 \mathrm{~Hz}$. Dynamic calibration of the motion capture system was performed before each data collection session.

Lower extremity segments were modelled in 6 degrees of freedom using the calibrated anatomical systems technique (Cappozzo et al., 1995). To define the segment co-ordinate axes of the foot, shank and thigh, retroreflective markers were placed bilaterally onto 1 st metatarsal, 5th metatarsal, calcaneus, medial and lateral malleoli, medial and lateral epicondyles of the femur. To define the pelvis segment further markers were posited onto the anterior (ASIS) and posterior (PSIS) superior iliac spines. Carbon fiber tracking clusters were positioned onto the shank and thigh segments. The foot was tracked using the 1st metatarsal, 5th metatarsal and calcaneus markers and the pelvis using the ASIS and PSIS markers. The centers of the ankle and knee joints were delineated as the mid-point between the malleoli anatomical markers to be referenced in relation to the tracking markers/ clusters.

Data were collected during run, cut and jump movements according to below:

Run

Participants ran at $4.0 \mathrm{~m} / \mathrm{s} \pm 5 \%$ and struck the force platform with their right (dominant) limb 
from the force platform. The average velocity of running was monitored using infra-red timing gates (SmartSpeed Ltd UK). The stance phase of running was defined as the duration over $>20 \mathrm{~N}$ of vertical force was applied to the force platform.

\section{Cut}

For the cut movement participants used an approach velocity of $4.0 \mathrm{~m} / \mathrm{s} \pm 5 \%$ and struck the force platform with their right (dominant) limb (Sinclair et al., 2015). Participants were required change direction to the opposite side at a $45^{\circ}$ angle. As with the run movement participants commenced their movement a minimum of 20 feet away from the force platform.

Cut angles were measured from the centre of the force plate and the corresponding line of movement was delineated using masking tape so that it was clearly evident to participants. The stance phase of the cut-movement was similarly defined as the duration over $>20 \mathrm{~N}$ of vertical force was applied to the force platform.

\section{Jump}

Participants completed counter movement vertical jumps in which they were required to use full arm swing and also to commence and land the jump on the force platform. The landing phase of the jump movement was quantified and was considered to have begun when $>20 \mathrm{~N}$ of vertical force was applied to the force platform and ended at point of maximum knee flexion.

\section{Processing}



movement. To accomplish this we firstly had to quantify the tibia-anterior shear force (TASF), which was undertaken using a modified version of the model described in detail by

Devita \& Hortobagyi, (2001). Our model differed only in that gender specific estimates of posterior tibial plateau slope (Hohmann et al., 2011), hamstring-tibia shaft angle (Lin et al., 2009) and patellar tendon-tibia shaft angle (Nunley et al., 2003) were utilized.

ACL loading was determined as the sum of ACL forces caused by the TASF, transverse plane knee moment, and coronal plane knee moment in accordance with the below equation.

ACL load $=(F 100 / 100 *$ TASF $)+(F 10 T V / 10 *$ transverse plane knee moment $)+(F 10 C R$ / $10 *$ coronal plane knee moment)

The components of the above equation were obtained using the data described by Markolf et al., (1995), who examined ACL forces in vitro when a $100 \mathrm{~N}$ TASF (F100) was applied to cadaver knees from $0-90^{\circ}$ of knee flexion. ACL forces were also measured when additional torques of $10 \mathrm{Nm}$ in the coronal $(F 10 C R)$ and transverse (F10TV) planes were combined with the $100 \mathrm{~N}$ TASF from $0-90^{\circ}$ of knee flexion.

179 All force parameters were normalized by dividing the net values by body mass (N/kg). From the musculoskeletal models peak ACL was extracted. In addition ACL average and instantaneous load rates $(\mathrm{N} / \mathrm{kg} / \mathrm{s})$ were quantified. Average load rate was obtained by dividing 
182

183

184

185

186

187

188

189

190

191

192

193

194

195

196

197 Results

198

199

200

201

202

the peak ACL force by the duration over which the force occurred and instantaneous load rate was quantified as the peak increase in force between adjacent data points.

\section{Statistical analyses}

Descriptive statistics of means, standard deviations $(S D)$ and $95 \%$ confidence intervals (95\% CI) were obtained for each outcome measure. Shapiro-Wilk tests were used to screen the data for normality. Differences in ACL parameters were explored using 2 (Sleeve) x 3 (Movement) repeated measures analysis of variance (ANOVA) with statistical significance accepted at the $\mathrm{p} \leq 0.05$ (Sinclair et al., 2013). Post-hoc analysis on significant main effects were undertaken in the form of pairwise comparisons. Significant interactions were further evaluated by performing simple main effect examinations on each level of the interaction, in the event of a significant simple main effect pairwise comparisons were performed. Effect sizes were calculated using partial $\operatorname{Eta}^{2}\left(\mathrm{p \eta}^{2}\right)$. All statistical actions were conducted using SPSS v23.0 (SPSS Inc, Chicago, USA).

Table 1 displays ACL loading parameters as a function of the knee sleeve and different movements. The findings show that ACL loading was influenced as a function of both the knee sleeve and the different movements. 
204 For peak ACL force a significant main effect $\left(\mathrm{P}<0.05, \mathrm{p}^{2}=0.70\right)$ was observed for

205

206

207

208

209

210

211

212

214

215

216

217

218

219

220

221

222

223

224

225

226 'movement', which showed that peak ACL force was significantly larger in the hop movement in comparison to the run $(\mathrm{P}=0.00000001)$ and cut $(\mathrm{P}=0.0002)$ conditions and in the cut movement compared to the run $(\mathrm{P}=0.004)$.

For average load rate a significant main effect $\left(\mathrm{P}<0.05, \mathrm{p}^{2}=0.22\right)$ was noted for 'sleeve'. With average load rate being significantly reduced in the sleeve condition. In addition there was also a significant main effect $\left(\mathrm{P}<0.05, \mathrm{p \eta}^{2}=0.49\right)$ for 'movement', which showed that average load rate was significantly larger in the hop movement in comparison to the run $(\mathrm{P}=0.001)$ and cut $(\mathrm{P}=0.0003)$ conditions. Finally, a significant sleeve*movement interaction $\left(\mathrm{P}<0.05, \mathrm{p} \eta^{2}=0.19\right)$ was also observed. Further analysis using simple main effects showed in the cut $\left(\mathrm{P}=0.004, \mathrm{p} \eta^{2}=0.40\right)$ and hop $\left(\mathrm{P}=0.03, \mathrm{p}^{2}=0.25\right)$ movements that the average ACL load rate was significantly reduced in the sleeve condition. However, in the run movement $\left(\mathrm{P}=0.46, \mathrm{p} \eta^{2}=0.03\right)$ no differences were found between the sleeve and no-sleeve conditions.

For instantaneous load rate a significant main effect $\left(\mathrm{P}<0.05, \mathrm{p} \eta^{2}=0.25\right)$ was noted for 'sleeve', load rate being significantly reduced in the sleeve condition. In addition there was also a significant main effect $\left(\mathrm{P}<0.05, \mathrm{p \eta}^{2}=0.65\right)$ for 'movement', which showed that instantaneous load rate was significantly larger in the hop movement in relation to the run $(\mathrm{P}=0.0000007)$ and cut $(\mathrm{P}=0.003)$ conditions and in the cut movement compared to the run $(\mathrm{P}=0.0001)$. Finally, a significant sleeve*movement interaction $\left(\mathrm{P}<0.05, \mathrm{p} \eta^{2}=0.23\right)$ was also observed. Further analysis using simple main effects showed in the cut $\left(\mathrm{P}=0.02, \mathrm{p} \eta^{2}=0.27\right)$ and hop $\left(\mathrm{P}=0.03, \mathrm{p}^{2}=0.26\right)$ movements that the instantaneous ACL load rate was 
significantly reduced in the sleeve condition. However, in the run movement $\left(\mathrm{P}=0.56, \mathrm{p} \eta^{2}=\right.$ 0.02) no differences were found between the sleeve and no-sleeve conditions.

\section{Discussion}

The aim of the current investigation was to examine the effects of a prophylactic knee sleeve on ACL loading parameters linked to the aetiology of injury in recreational athletes. To our knowledge this represents the first investigation to quantitatively analyze the effects of prophylactic knee sleeves on ACL loading during sports specific movements.

Importantly the current investigations showed that ACL average and instantaneous load rates were significantly reduced during the cut and hop movements when wearing the prophylactic sleeve. This observation is an interesting one in that the prophylactic knee sleeve served to mediate significant reductions in ACL loading parameters in the cut and hop movements, yet in the run condition there were no statistical improvements. As stated previously the mechanical aetiology of ACL injury in athletic populations is caused by excessive loading is of the ACL itself (Smith et al., 2012). Therefore, given the increased rate at which the ACL was loaded in the no-sleeve condition, this observation may be important clinically. It can be conjectured that ACL injury risk during specific athletic movements through may be attenuated through utilization of prophylactic knee sleeve.

An additional important observation from the current study is that, ACL loading parameters were all significantly greater in the cut and hop movements in comparison to the run condition. This observation agrees with previous conjecture which indicates that ACL injury 
risk is greatest in movements such as the cut and hop conditions which feature significant decelerations, landings and pivoting motions (Olsen et al., 2004). It is hypothesized that this finding relates to the ballistic nature of cut and leg hop conditions in relation to the running, which increase TASF and thus resistive ligamentous loading (Devita \& Hortobagyi, 2001). Because the ACL injuries are linked to excessive loading of the ligament itself (Smith et al., 2012), the current study indicates that athletic disciplines which feature a significant number of cut and hop motions may place athletes at increased risk from ACL injury.

In conclusion, although previous investigations have examined the efficacy of prophylactic knee bracing, our current knowledge regarding their effects on the ACL in functional athletic movements is limited. As such the current work addresses this by examining the influence of a prophylactic knee sleeve on ACL loading parameters during run, cut and jump movements. The current study importantly showed that ACL loading parameters were significantly reduced in the hop and cut movements whilst wearing the knee sleeve. In addition it was also revealed that the cut and hop movements were associated with significantly greater ACL loading in relation to the run condition. Given the biomechanical association between ACL loading and the aetiology of ACL injuries, it is proposed that athletes may be able to attenuate their risk from injury during cut and hop movements through utilization of a prophylactic knee sleeve.

\section{References}


1. Schnohr, P., O'Keefe, J. H., Marott, J.L., Lange, P., Jensen, G.B. (2015). Dose of jogging and long-term mortality: the Copenhagen City Heart Study. Journal of the American College of Cardiology, 65, 411-419.

2. Lauersen, J.B., Bertelsen, D.M., \& Andersen, L.B. (2014). The effectiveness of 
9. Ajuied, A., Wong, F., Smith, C., Norris, M., Earnshaw, P., Back, D., \& Davies, A. (2014). Anterior cruciate ligament injury and radiologic progression of knee osteoarthritis: a systematic review and meta-analysis. The American Journal of Sports Medicine, 42, 2242-2252.

10. Gottlob, C.A., Baker Jr, C.L., Pellissier, J.M., \& Colvin, L. (1999). Cost effectiveness of anterior cruciate ligament reconstruction in young adults. Clinical Orthopaedics and Related Research, 367, 272-282.

11. Boden, B. P., Torg, J. S., Knowles, S. B., \& Hewett, T. E. (2009). Video analysis of anterior cruciate ligament injury abnormalities in hip and ankle kinematics. The American Journal of Sports Medicine, 37, 252-259.

12. Smith, H. C., Vacek, P., Johnson, R. J., Slauterbeck, J. R., Hashemi, J., Shultz, S., \& Beynnon, B. D. (2012). Risk factors for anterior cruciate ligament injury: a review of the literature-part 1: neuromuscular and anatomic risk. Sports Health, 4, 69-78.

13. Olsen, O. E., Myklebust, G., Engebretsen, L., \& Bahr, R. (2004). Injury mechanisms for anterior cruciate ligament injuries in team handball a systematic video analysis. The American Journal of Sports Medicine, 32, 1002-1012.

14. Sinclair, J., Vincent, H., \& Richards, J. D. (2017). Effects of prophylactic knee bracing on knee joint kinetics and kinematics during netball specific movements. Physical Therapy in Sport, 23, 93-98.

15. Jackson, R. W., Reed, S. C., \& Dunbar, F. (1991). An Evaluation of Knee Injuries in a Professional Football Team-Risk Factors, Type of Injuries, and the Value of Prophylactic Knee Bracing. Clinical Journal of Sport Medicine, 1, 1-7.

16. Sitler, M., Ryan, C. J., Hopkinson, L. W., Wheeler, L. J., Santomier, J., Kolb, L. R., \& Polley, C. D. (1990). The efficacy of a prophylactic knee brace to reduce knee injuries 
in football: a prospective, randomized study at West Point. The American journal of sports medicine, $18,310-315$.

17. Erickson, A. R., Yasuda, K., Beynnon, B. D., Johnson, R. J., \& Pope, M. H. (1993). Dynamic elongation behavior in the medical collateral and anterior cruciate ligaments during lateral impact loading. Journal of orthopaedic research, 11, 190-198.

18. Raja, K., \& Dewan, N. (2011). Efficacy of knee braces and foot orthoses in conservative management of knee osteoarthritis: a systematic review. American journal of physical medicine \& rehabilitation, 90, 247-262.

19. Cappozzo, A., Catani, F., Leardini, A., Benedeti, M.G., Della, C.U. (1995). Position and orientation in space of bones during movement: Anatomical frame definition and determination. Clinical Biomechanics, 10, 171-178.

20. Sinclair, J., Hobbs, S. J., Taylor, P. J., Currigan, G., \& Greenhalgh, A. (2014). The influence of different force and pressure measuring transducers on lower extremity kinematics measured during running. Journal of applied biomechanics, 30(1), 166172.

21. DeVita, P., \& Hortobagyi, T. (2001). Functional knee brace alters predicted knee muscle and joint forces in people with ACL reconstruction during walking. Journal of Applied Biomechanics, 17, 297-311.

22. Hohmann, E., Bryant, A., Reaburn, P., \& Tetsworth, K. (2011). Is there a correlation between posterior tibial slope and non-contact anterior cruciate ligament injuries?. Knee Surgery, Sports Traumatology, Arthroscopy, 19 109-114.

23. Lim, B. O., Lee, Y. S., Kim, J. G., An, K. O., Yoo, J., \& Kwon, Y. H. (2009). Effects of sports injury prevention training on the biomechanical risk factors of anterior cruciate ligament injury in high school female basketball players. The American journal of sports medicine, 37, 1728-1734. 
24. Nunley, R. M., Wright, D., Renner, J. B., Yu, B., \& Garrett Jr, W. E. (2003). Gender comparison of patellar tendon tibial shaft angle with weight bearing. Research in Sports Medicine, 11, 173-185.

25. Markolf, K. L., Burchfield, D. M., Shapiro, M. M., Shepard, M. F., Finerman, G. A., \& Slauterbeck, J. L. (1995). Combined knee loading states that generate high anterior cruciate ligament forces. Journal of Orthopaedic Research, 13, 930-935.

26. Sinclair, J., Taylor, P. J., \& Hobbs, S. J. (2013). Alpha level adjustments for multiple dependent variable analyses and their applicability-a review. International Journal of 
Table 1: ACL loading parameters as a function of the knee sleeve and different movements.

\begin{tabular}{|c|c|c|c|c|c|c|c|c|c|c|c|c|c|c|c|c|c|c|}
\hline & \multicolumn{6}{|c|}{ Run } & \multicolumn{6}{|c|}{ Cut } & \multicolumn{6}{|c|}{ Hop } \\
\hline & \multicolumn{3}{|c|}{ No-Sleeve } & \multicolumn{3}{|c|}{ Sleeve } & \multicolumn{3}{|c|}{ No-Sleeve } & \multicolumn{3}{|c|}{ Sleeve } & \multicolumn{3}{|c|}{ No-Sleeve } & \multicolumn{3}{|c|}{ Sleeve } \\
\hline & Mean & $S D$ & $\begin{array}{c}95 \% \\
\text { CI } \\
\end{array}$ & Mean & $S D$ & $\begin{array}{c}95 \% \\
\text { CI }\end{array}$ & Mean & $S D$ & $\begin{array}{c}95 \% \\
\text { CI } \\
\end{array}$ & Mean & $S D$ & $\begin{array}{c}95 \% \\
\text { CI } \\
\end{array}$ & Mean & $S D$ & $\begin{array}{c}95 \% \\
\text { CI } \\
\end{array}$ & Mean & $S D$ & $\begin{array}{c}95 \% \\
\text { CI } \\
\end{array}$ \\
\hline $\begin{array}{c}\text { Peak ACL force } \\
(\mathrm{N} / \mathrm{kg})\end{array}$ & 12.57 & 1.92 & $\begin{array}{l}10.62- \\
12.52 \\
\end{array}$ & 12.49 & 3.37 & $\begin{array}{c}10.71- \\
14.06 \\
\end{array}$ & 14.34 & 2.36 & $\begin{array}{r}13.17- \\
15.52 \\
\end{array}$ & 14.20 & 2.98 & $\begin{array}{c}12.72- \\
15.68 \\
\end{array}$ & 18.76 & 4.43 & $\begin{array}{l}16.55- \\
20.96 \\
\end{array}$ & 18.67 & 2.58 & $\begin{array}{r}17.39- \\
19.96 \\
\end{array}$ \\
\hline $\begin{array}{c}\text { ACL load rate } \\
(\mathrm{N} / \mathrm{kg} / \mathrm{s})\end{array}$ & 267.76 & 146.95 & $\begin{array}{l}164.68- \\
310.83 \\
\end{array}$ & 263.57 & 259.76 & $\begin{array}{l}144.40- \\
402.75 \\
\end{array}$ & 377.38 & 222.73 & $\begin{array}{l}266.62- \\
488.14 \\
\end{array}$ & 222.55 & 62.17 & $\begin{array}{l}191.64- \\
253.47 \\
\end{array}$ & 743.91 & 532.24 & $\begin{array}{l}479.23- \\
1008.59 \\
\end{array}$ & 612.45 & 422.87 & $\begin{array}{l}402.17- \\
822.74 \\
\end{array}$ \\
\hline $\begin{array}{c}\text { ACL } \\
\text { instantaneous load } \\
\text { rate }(\mathrm{N} / \mathrm{kg} / \mathrm{s}) \\
\end{array}$ & 813.00 & 228.39 & $\begin{array}{l}699.42- \\
926.57\end{array}$ & 810.66 & 327.87 & $\begin{array}{l}677.62- \\
1003.71\end{array}$ & 1183.01 & 335.54 & $\begin{array}{l}1016.15- \\
1349.96\end{array}$ & 1058.02 & 270.70 & $\begin{array}{l}923.40- \\
1192.64\end{array}$ & 1471.42 & 544.19 & $\begin{array}{c}1200.79- \\
1742.04\end{array}$ & 1286.39 & 344.11 & $\begin{array}{l}1115.27 \\
1457.52\end{array}$ \\
\hline
\end{tabular}

